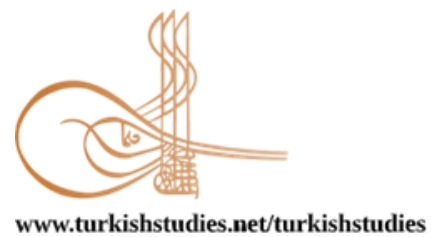

Turkish Studies

\title{
Koronavirüs (COVID-19) Salgınında Sosyodemografik Özellikler, Psikolojik Sağlamlık ve Kaygı Düzeyleri Arasındaki İlişsi
}

\author{
Relationship Between Sociodemographic Characteristics, Psychological Resilience and Anxiety \\ Levels in the Coronavirus (COVID-19) Outbreak
}

\author{
Taner Artan ${ }^{*}-$ Irmak Atak $^{* *}$ - Merve Karaman ${ }^{* * *}$ - Fatih Cebeci ${ }^{* * * *}$
}

\begin{abstract}
In recent days, the whole world is under the influence of the quickly spreading Covid-19. The aim of this study is to analyze the effect this highly infectious disease on individuals living in Turkey. This was achieved by focusing on the relationship between the participants' psychological resilience and anxiety levels and also their socio-demographic characteristics. The study sample consisted of 525 individuals with ages ranging between 15 and 72, who live in various provinces of Turkey. Ethics committee approval and scientific research approval were obtained. Participants were reached through random sampling, via an electronic-based survey method (Google Forms). As a data collection tool; a personal information form, Short Psychological Resilience Scale (KPSÖ) and Beck Anxiety Inventory (BAI) were used. The Spearman correlation analysis showed that anxiety decreases as the psychological resilience of the participants increases $(\mathrm{r}=-0.453, \mathrm{p}<0.01)$. As the participants' perception of possibility to catch COVID-19 increases, their anxiety increases $(\mathrm{r}=0.177, \mathrm{p}<0.01)$. In addition, as psychological resilience increases, preventive behavior also increases $(r=0.103, p<0.01)$. It was learned that $95.8 \%$ of the participants started to wash their hands more frequently during the epidemic period and $93.7 \%$ of them avoided shaking hands. The anxiety levels of the group $(77.7 \%)$ with economic concerns regarding the epidemic process were significantly higher $(\mathrm{p}=0.002)$. As a result, it was concluded that anxiety levels decreased as the psychological resilience level of
\end{abstract}

\footnotetext{
* Doç. Dr., İstanbul Üniversitesi - Cerrahpaşa, Sağlık Bilimleri Fakültesi, Sosyal Hizmet Bölümü Assoc. Prof. Dr., Istanbul University-Cerrahpașa, Faculty of Health Sciences, Department of Social Work ORCID 0000-0002-8716-2090

taner.artan@istanbul.edu.tr

** Doktora Öğrencisi, İstanbul Sabahattin Zaim Üniversitesi, Sağllk Bilimleri Fakültesi, Sosyal Hizmet Bölümü Ph.D. Candidate, Istanbul Sabahattin Zaim University, Faculty of Health Sciences, Department of Social Work ORCID 0000-0001-5427-4355

psk.irmak.arslan@gmail.com

**** Doktora Öğrencisi, İstanbul Üniversitesi- Cerrahpaşa, Sağlık Bilimleri Fakültesi, Sosyal Hizmet Bölümü Ph.D. Candidate, Istanbul University-Cerrahpaşa, Faculty of Health Sciences, Department of Social Work ORCID 0000-0002-3210-3325 merve.389206@gmail.com

**** Doktora Öğrencisi, İstanbul Üniversitesi- Cerrahpaşa, Sağllk Bilimleri Fakültesi, Sosyal Hizmet Bölümü Ph.D. Candidate, Istanbul University-Cerrahpaşa, Faculty of Health Sciences, Department of Social Work ORCID 0000-0003-3866-5967

fatihalpcebeci@gmail.com
}

Cite as/ Atıf: Artan, T., Atak, I., Karaman M. \& Cebeci, F. (2020). Koronavirüs (COVID-19) salgınında sosyodemografik özellikler, psikolojik sağlamlık ve kaygı düzeyleri arasındaki ilişki. Turkish Studies, 15(6), 79-94. https://dx.doi.org/10.7827/TurkishStudies.43882

Received/Geliș: 31 May/Mayıs 2020

Accepted/Kabul: 15 October/Ekim 2020

Copyright $(\mathrm{C}$ MDE, Turkey

\section{Copyright}


the participants increased. As the participants' perception of the possibility of getting COVID-19 increased, it was found that their anxiety increased. In the COVID-19 pandemic, women had higher anxiety levels than men and it was found that women had a lower level of psychological resilience. On the other hand; it has been determined that the number of people living at home, participants' being married or single, their education level and the province they live in didn't affect the anxiety and psychological resilience levels of the participants.

Structured Abstract: Purpose: An infection that first started with suspicious cases in Wuhan, China in midNovember 2019 was soon identified as COVID-19 (SARS-Cov2 Infection) in December 2019. With the rapid spread of COVID-19 globally, it was announced by the World Health Organization on 30.01.2020 that it was declared an "international public health emergency". Subsequent to, the global risk level was increased to "very high" level on 28.02.2020, and the epidemic of COVID-19 was declared as a pandemic on 11.03.2020. Pandemic is the generic term given to epidemics that affect a wide range of fields and affect more than one country or continent in the world. In such cases, the mental health of a society can be severely affected, and psychosocial support studies may be required by mental health professionals. Psychosocial interventions include increasing strategies for coping with individual, family and society and supporting the psychological well-being of individuals in the encountering of challenging life events. In the process of Covid-19 pandemics measures were taken seriously both in Turkey and all over the world. Turkey also severely affected schools closed due to the outbreak; introduced a flexible working system in public and many other institutions; curfews have been restricted to citizens under the age of 20 and over 65, curfews have been imposed on weekends and intercity transportation has been closed. In the light of all these precautions, it has been a matter of curiosity about how many changes in the new lifestyle that individuals face during the pandemic period affected our lives.

In line with the general purpose of the research; the answers to some questions of what measures individuals take within the scope of COVID-19 measures, the relationship between individuals' psychological resilience levels and anxiety levels, and whether the mental resilience and anxiety levels of individuals change according to the socio-demographic characteristics of the COVID-19 pandemic have been sought.

\section{Method}

The study population is 525 individuals who live in various provinces of Turkey, ages ranging from between 15 and 72. Ethics committee approval from Istanbul Sabahattin Zaim University and scientific research approval from Turkish Ministry of Health were obtained. The participants were contacted via random sampling, through the electronic-based survey method (via Google Forms) between 23-30 March 2020. As a data collection tool; personal information form, The Brief Resilience Scale (BRS) and Beck Anxiety Inventory (BAI) were used. The information form, filled out by the people participating in the study, was prepared by the researchers. After the participants read the informed consent form, "I was informed about the research. I agree to participate. " started to work by answering "yes" to the statement. In the form prepared in the scope of the research, in addition to the questions such as age, gender, educational status, marital status, educational level, health status, and economic status of the participants; there are also questions about various situations that may have been affected by the epidemic process. In this context, 16 questions were asked to participants whether there was any change in their work-life during the epidemic period and what preventive behaviours they took towards COVID-19. The analysis of the data was carried out through the SPSS 22.0 for Windows program. First of all, descriptive statistics are presented to describe the expressive features of the participants, and then hypothesis tests are included. In all analyses, the level of significance was determined as $\mathrm{p}<0.05$ or $\mathrm{p}<0.01$. Whether the obtained data shows that normal distribution was examined with the Kolmogorov-Smirnov Test and non-parametric analysis tests were used since the data did not show normal distribution. According to the non-parametric test assumptions, Spearman's correlation analysis, in order to reveal the relationship between the two scales, the Mann Whitney U Test in the comparison of the mean scores obtained by the binary groups (gender, etc.) from continuous data; Kruskal Wallis $\mathrm{H}$-Test was used to compare the averages of the ratings received by more than two groups (educational status, etc.) from continuous data.

\section{Results and Discussion}

Spearman correlation analysis shows that the anxiety decreases as the psychological resilience of the participants increases $(r=-0.453, p<0.01)$. As the perception of the participants increased the probability of getting COVID-19, their anxiety increased $(r=0.177, \mathrm{p}<0.01)$. In addition, as psychological resilience 
increases, preventive behavior increases $(\mathrm{r}=0.103, \mathrm{p}<0.01)$. It was learned that $95.8 \%$ of the participants started to wash their hands more frequently during the epidemic process, and $93.7 \%$ of them avoided shaking hands. The anxiety levels of the group $(77.7 \%)$ with economic concerns regarding the epidemic process were significantly higher $(\mathrm{p}=0.002)$. The anxiety levels and psychological resilience levels of the group who thought that they could communicate adequately with their relatives during the epidemic period were found to be lower than those who did not. In other words, individuals who communicate with their relatives (on the phone, on the internet) during the epidemic have less anxiety and at the same time have higher psychological resilience. It was seen from the participants that the group working full time in the private and public sector constitutes the highest segment, and the students follow them. After the outbreak, $72.4 \%(\mathrm{~N}=220)$ of the working participants had a change in their working status. While only $5.5 \%$ of this group stated that they were dismissed or had to close their jobs, it was learned that a large number of remote working systems were introduced.

\section{Conclusion}

As a result of the analysis carried out, it was concluded that the level of anxiety decreased as the level of psychological resilience of the participants increased. It was found that as the participants' perception of the possibility of catching COVID-19 increased, their anxiety increased. In the COVID-19 pandemic, anxiety levels of women were higher than men, and it was found that women had lower levels of psychological resilience. On the other hand; it has been determined that the number of people living at home, participants' being married or single, their education level and the province they live in did not affect the anxiety and psychological resilience levels of the participants. During the pandemic and the results obtained in the study reveal the outcome of Turkey's resilience and anxiety; on the other hand, is expected to provide benefits in terms of literature to show the results occurring in our lives. Considering that individuals may lose their ability to adapt to stressful situations and cause anxiety disorders if anxiety level increases, especially in these severe conditions, they must be continued to work to ensure the continuity of public health and order. We suggest that psychosocial support activities provide rigorously for those who lose their relatives due to COVID-19 during the epidemic process and after.

Keywords: social work, coronavirus (COVID-19), anxiety, psychological resilience, pandemic

Öz: Bu çalışmanın amacı; son günlerde tüm dünyayı etkisi altına alan ve hızlı bir şekilde yayılan COVID-19 salgını sürecinde Türkiye'de yaşayan bireylerin sosyodemografik özellikleri ile psikolojik sağlamlıkları ve kaygı düzeyleri arasındaki ilişkinin incelenmesidir. Çalışmanın evrenini, Türkiye'nin çeşitli illerinde yaşamakta olan, yaşları 15 ile 72 arasında değişen 525 birey oluşturmaktadır. Araştırma kapsamında, bilimsel araştırma onayı ve etik kurul onayı alınmıştır. Katılımcılara tesadüfi örnekleme yoluyla, elektronik tabanlı anket yöntemiyle (Google Forms aracılığıla) ulaşılmıştır. Veri toplama aracı olarak; kişisel bilgi formu, Kısa Psikolojik Sağlamlık Ölçeği (KPSÖ) ve Beck Anksiyete Ölçeği (BAÖ) kullanılmıştır. Spearman korelasyon analizi, katılımcıların psikolojik sağlamlıkları arttıkça anksiyetelerinin düştüğünü göstermektedir $(\mathrm{r}=-0.453, \mathrm{p}<0.01)$. Katılımcıların COVID-19'a yakalanabilme algısı arttıkça anksiyeteleri artmaktadır $(\mathrm{r}=$ $0.177, \mathrm{p}<0.01)$. Ayrıca psikolojik sağlamlık arttıkça önleyici davranışları da artmaktadır $(\mathrm{r}=0.103, \mathrm{p}<0.01)$. Katılımcıların \%95.8'inin salgın sürecinde ellerini daha sık yıkamaya başladıkları, \%93.7'sinin el sıkışmaktan kaçındığı öğrenilmiştir. Salgın sürecine dair ekonomik endişesi olan grubun (\%77.7) kaygı düzeyleri anlamlı derecede daha yüksek bulunmuştur $(\mathrm{p}=0.002)$. Gerçekleştirilen analizler sonucunda katılımcıların psikolojik sağlamlık düzeyi arttıkça kaygı düzeylerinin azaldığı sonucuna ulaşılmıştır. Katılımcıların COVID-19'a yakalanacağı ihtimali yönündeki algısı arttıkça kaygılarının da arttı̆̆ tespit edilmiştir. COVID-19 pandemisinde kadınların erkeklere göre kaygı düzeylerinin daha yüksek olduğu görülmüş ve kadınların psikolojik sağlamlık düzeylerinin daha düşük olduğu bulgulanmıştır. Öte yandan; evde yaşayan kişi sayısı, katılımcıların evli ya da bekar olma durumu, eğitim düzeyleri ve yaşadıkları ilin katılımcıların kaygı ve psikolojik sağlamlık düzeylerini etkilemediği tespit edilmiştir.

Anahtar Kelimeler: sosyal hizmet, koronavirüs (COVID-19), anksiyete, psikolojik sağlamllk, pandemi 


\section{Giriş}

2019 yılının Kasım ayının ortalarında Çin'in Wuhan kentinde ilk olarak şüpheli vakalarla başlayan bir enfeksiyon çok geçmeden 2019 Aralık'ta COVID-19 (SARS-Cov2 Enfeksiyonu) olarak tanımlanmıştır (Ankaralı, Ankaralı \& Eraslan, 2020). Dünya Sağlık Örgütü koronavirüsler hakkında yaptığı açıklamasında bu virüs ailesinin insanlarda ve hayvanlarda hastalığa neden olabilecek büyük bir virüs grubu olduğunu, bu koronavirüslerin insanlarda neden olduğu solunum yolu hastalıklarından bazılarının Orta Doğu Solunum Sendromu (MERS) ve Şiddetli Akut Solunum Sendromu (SARS) gibi ciddi hastalıklar olduğunu belirtmiştir. En son olarakta bu virüs ailesinden olan ve COVID-19 olarak adlandırılan solunum yolu hastalığının yayılmasıyla birlikte Dünya Sağlık Örgütü tarafından 30.01.2020 tarihinde bu salgınla ilgili "uluslararası kamu sağlığı acil durumu" ilan edildiği duyurulmuş, daha sonra 28.02.2020 tarihinde küresel risk seviyesi "çok yüksek" seviyesine çıkarılmış ve COVID-19 salgını 11.03.2020 tarihinde pandemi olarak ilan edilmiştir (Bag, 2020).

Bilindiği üzere pandemi çok geniş bir alanda etkili olan, dünyada birden fazla ülke ya da kıtayı etkileyen salgın hastalıklara verilen genel isimdir. Bir toplumda mevcut düzenin sürekliliğini ciddi bir biçimde bozan, yaşamın doğal işleyişinde kesintiye neden olan ya da durduran veya ekonomik, sosyal ve çevresel kayıpların yanı sıra ciddi oranda insan kaybı, hastalık, yaralanma, bireylerin fiziksel ve ruhsal sağlıklarını etkileyen durumlar afet kavramının özellikleri olarak tanımlanmıştır. $\mathrm{Bu}$ bağlamda afetler yapısı gereği, büyük insan kitlelerini etkileyebilen ve çoğunlukla ani gelişen travmatik olaylar olarak görülmektedir. Buradaki önemli husus; afet ve acil durumların travmatik olaylardan biri olduğu ve bir ruhsal hastalık olan travma sonrası stres bozukluluğu (TSSB) ile karıştırılmadan meslek elemanlarının psikososyal destek vermesi gerektiğidir. Meslek elemanının bu iki durum arasındaki farkı iyi gözlemleyebilmesi ve birbirinden ayırt edebilmesi önemlidir (Alakara Özcan, 2018). Çünkü sosyal hizmet disiplini, bir meslek olarak odağına "insan"ı alarak onun bedensel, ruhsal ve sosyal yönden tam bir iyilik halinde olmasını amaç edinir (Lofti, 2017). International Federation of Red Cross (IFRC) ise bireylerin afet ve acil durumlar sonrası toparlanması, birey, aile ve toplum bazında başa çıkma stratejilerinin artırılması ve psikolojik sağlamlıklarının desteklenmesini psikososyal müdahaleler olarak görmektedir (IFRC, 2019). Söz konusu COVID-19 pandemisinin de bireylerin fiziksel ve ruhsal sağlıklarını etkileyen ve ani gelişen, beklenmedik bir durum olması, ciddi insan kayıplarına yol açması ve tüm dünyada karantina, iş yaşamında değişiklik, sokağa çıkma yasaklamaları gibi ciddi önlemlerin alınmasına yol açması sebebiyle psikososyal desteğe olan ihtiyacı da gündeme getirmiştir.

Diğer yandan uzun süredir araştırmaların odaklandığı psikolojik sağlamlık kavramı değişik şekillerde tanımlanmıştır (Özer, 2016). Ruh sağlığı açısından çok önemli bir kavram olan psikolojik sağlamlık, bireylerin olumsuz ve zor durumlar karşısında mevcut olumsuz durumların başarıyla üstesinden gelebilme ve bu koşullara uyum sağlayabilme becerisi olarak kabul edilir. Yapılan araştırmalarda psikolojik sağlamlıkları yüksek bireylerin hastalık gibi zorlayıcı yaşam olayları karşısında daha iyi mücadele edebildikleri görülmüştür (Öz \& Bahadır Yılmaz, 2019). Kaygı kavramı ise insanın ruhsal durumunu ifade eden ve herhangi bir tehlike karşısında insanda bir korku yansıması ve tedirginlik hali olarak ortaya çıkan bir durum olarak tanımlanmıştır (Manay, 2011). Freud'a göre kayg1, çevreden gelen tehditler için kişiyi uyararak gereken uyumu sağlamasına ve bireyin sağlıklı bir biçimde hayatını sürdürmesine katkıda bulunur. Fakat bu uyum sağlama durumu işlevini kaybeder ve mantıkdışı bir hal alırsa normal dışı davranışlar ortaya çıkar (Geçtan, 2012). Kaygı kavram olarak beraberinde korku duygusunu barındırmakla birlikte aslında insan vücudunun zorlu bir yaşam olayına veya stres durumuna karşı verdiği doğal bir tepkidir. Sıradan bir kayg1 normal bir duygu olarak görünmekte ve günlük yaşamı etkilemediği düşünülmektedir. Kaygı halinin aşırı yükselerek bireylerin yaşamlarına müdahale etmesi durumunda ise çeşitli anksiyete bozuklukları ortaya çıkmaktadır (Holland, 2019). Benzer psikososyal süreçlerin de COVID-19 salgınında geçerli olabileceği söylenebilir. 
COVID-19 salgınında 23.01.2020 tarihinde Çin'in Wuhan kenti için “lock-down (kilitlenme)" kararı alınıp uygulamaya konulmuştur. Diğer bir deyişle Wuhan karantina altına alınmıştır (Karcıoğlu, 2020). Salgının bir pandemiye dönüşmesiyle birlikte diğer ülkelerin de benzeri uygulamalarla salgınla baş etme ve salgının yayılmasını önlemeye yönelik tedbirler aldığı görülmüştür. Türkiye'de ilk COVID-19 teşhisinin 11 Mart 2020 tarihinde konulması ile birlikte çeşitli tedbirler alınmış ve salgının ilk ayında Türkiye'de yaşayan bireylerin hayatlarında ciddi değişiklikler meydana gelmiştir (Budak \& Korkmaz, 2020). Araştırmanın genel amacı doğrultusunda; Türkiye'de bireylerin COVID-19 tedbirleri kapsamında aldıkları önlemlerin neler olduğu, bireylerin psikolojik sağlamlık düzeyleri ve kaygı düzeyleri arasında nasıl bir ilişki olduğu ve COVID-19 pandemisi sürecinde bireylerin psikolojik sağlamlık ve anksiyete düzeylerinin sosyo-demografik özelliklerine göre değişip değişmediği sorularına cevap aranmıştır. Ayrıca araştırma bulgularının; bireylere, ailelere ve topluma yönelik sunulacak psiko-sosyal destek çalışmalarına katkı sağlayacağı düşünülmektedir.

\section{Yöntem}

Çalışmada tesadüfi örnekleme yöntemi kullanılarak 23-30 Mart 2020 tarihleri arasında internet tabanlı anket yoluyla (Google Forms) veri toplanmıştır. Çalışmaya dair; COVID-19 ile ilgili araştırmalar kapsamında T.C. Sağlık Bakanlığı Sağlık Hizmetleri Genel Müdürlüğü’nden 2020-05-06-T15_38_43 No'lu başvuru ile 27.05.2020 tarihinde bilimsel araştırma onayı ve İstanbul Sabahattin Zaim Üniversitesi'nden 29.05.2020 tarih ve 2020/05 say1l etik kurul onay1 alınmıştır. Çalışmanın evreni, Türkiye'de yaşamakta olan 15 ile 72 yaş aralı̆̆ındaki (Ort. $=32.63$, SS = 13.12) bireylerden oluşmaktadır. Çalışmaya gönüllülük esasına göre 525 kişi katılmıştır. Veri toplama aracı olarak; "Kişisel Bilgi Formu", "Kısa Psikolojik Sağlamlık Ölçeği” (KPSÖ) ve "Beck Anksiyete Ölçeğì" (BAÖ) kullanılmıştır.

\section{Araştırma Hipotezleri}

Araştırmanın amacı ve mevcut alanyazın doğrultusunda bir dizi hipotez hazırlanmıştır. Toplanan veriler ile cevaplanması arzulanan hipotezler:

Koronavirüs (COVID-19) salgını sürecinde;

1.Bireylerin psikolojik sağlamlık düzeyleri arttıkça anksiyete düzeyleri azalmaktadır.

2.Bireylerin psikolojik sağlamlık düzeyleri arttıkça önleyici davranışlarda bulunma düzeyleri artmaktadır.

3.Bireylerin anksiyete düzeyleri arttıkça önleyici davranışlarda bulunma düzeyleri artmaktadır.

4.Bireylerin COVID-19'a yakalanma ihtimali yönündeki algıları arttıkça anksiyete düzeyleri artmaktadır.

5.Bireylerin COVID-19'a yakalanma ihtimali yönündeki algıları arttıkça psikolojik sağlamlık düzeyleri azalmaktadır.

\section{Kişisel Bilgi Formu}

Çalışmaya katılan kişiler tarafından doldurulan bilgi formu araştırmacılar tarafından hazırlanmıştır. Katılımcılar bilgilendirilmiş onam formunu okuduktan sonra, "Araştırmayla ilgili bilgilendirildim. Katılmayı kabul ediyorum." ifadesine "evet" cevabını vererek çalışmaya başlamıştır. Araştırma kapsamında hazırlanmış olan formda katılımcıların yaş, cinsiyet, eğitim durumu, medeni hali, eğitim düzeyi, sağlık durumu, ekonomik durumu gibi sorulara ek olarak; salgın sürecinden etkilenmiş olabilecek çeşitli durumlar hakkında da sorular bulunmaktadır. $\mathrm{Bu}$ kapsamda ise katılımcılara, salgın döneminde iş yaşamlarında değişiklik olup olmadığı, COVID19’a yönelik hangi önleyici davranışlarda bulundukları tarzında 16 soru yöneltilmiştir.

\section{Kısa Psikolojik Sağlamlık Ölçeği (KPSÖ)}

Smith ve arkadaşları (2008) tarafindan kişilerin psikolojik sağlamlıklarını ölçme amacıyla geliştirilmiş olan ölçek, "1-Hiç uygun değil." ve "5-Tamamen uygun." arasında değişen 5'li likert 
tipinde 6 maddeden oluşmaktadır. Ölçekteki 2, 4 ve 6 . sorular ters kodlama gerektirmektedir. Ölçekten alınan puanların yüksek olması psikolojik sağlamlığın yüksek olduğunu göstermektedir. Ölçeğin geliştirilmesi ve geçerlik-güvenirlik çalışması kapsamında, iki farklı öğrenci grubu, kalp ve fibromiyalji hastaları olmak üzere dört farklı grup kullanılmıştır. Ölçeğin güvenirlik katsayısı $0.80-0.91$ arasında, test-tekrar test güvenirlik katsayısı ise $0.62-0.69$ arasında değerler olarak bulunmuştur.

Ölçeğin Türkçe geçerlik güvenirlik çalışması Doğan (2015) tarafından yapılmıştır. Bu çalışmada Kaiser-Meyer-Olkin (KMO) değeri 0.85 ve Barlett Küresellik Testi $\chi 2$ değeri 594,955 olarak bulunmuştur $(\mathrm{p}<.000)$. Yapılan açımlayıcı faktör analizi sonucu toplam varyansın \%54'ünü açıklayan tek faktörlü bir yapı elde edilmiştir. Türkçe formun Cronbach alfa güvenirliği 0.81 , iç tutarlık katsayısı 0.83 olarak tespit edilmiştir. Mevcut çalışma için bulunan Cronbach alfa değeri ise 0.79 'dur.

\section{Beck Anksiyete Ölçeği (BAÖ)}

Ölçek, Beck ve arkadaşları (1988) tarafından kişilerin anksiyete düzeylerini ölçmek amaciyla geliştirilmiştir. Kendini değerlendirme ölçeği olan BAÖ, 21 maddeden oluşan, "0 - hiç" ile " 3 - ciddi düzeyde" arasında sıklık belirtilen 4'lü likert tipi bir ölçektir. Ölçekte herhangi bir madde için ters kodlama gerekmemektedir. Ölçekten alınan yüksek puanlar, yüksek anksiyete düzeylerine işaret etmektedir. Ölçeğin Türkçe adaptasyon çalışması Ulusoy ve arkadaşları (1998) tarafından gerçekleştirilmiştir.

Orijinal ölçeğin güvenilirlik analizi kapsamında bulunan Cronbach alfa içsel tutarlılık katsayısı 0.92 ve test - tekrar test korelasyon katsayısı 0.75 'tir (14). Ölçeğin Türkçeye uyarlanmış formu için Cronbach alfa içsel tutarlılık katsayısı 0.93 olarak bulunmuştur (Ulusoy ve ark., 1988). Bu çalışma kapsamında bulunan Cronbach alfa değeri ise 0.91'dir.

\section{Verilerin Analizi}

Veri analizi SPSS 22.0 programı aracılığıyla gerçekleştirilmiştir. Öncelikle katılımcıların tanımlayıcı özelliklerinin betimsel olarak ortaya konabilmesi için betimleyici istatistiklere, sonrasında ise hipotez testlerine yer verilmiştir. Yapılan tüm analizlerde anlamlılık düzeyi $\mathrm{p}<0.05$ ya da $\mathrm{p}<0.01$ olarak belirlenmiştir. Elde edilen verilerin normal dağılım gösterip göstermediği Kolmogorov-Smirnov Testi ile incelenmiş ve veriler normal dağılım göstermediği için nonparametrik analiz testleri kullanılmıştır. Non-parametrik test varsayımlarına göre iki ölçekten alınan verilerin birbiriyle ilişkisinin ortaya konması için Spearman's korelasyon analizi, ikili grupların (cinsiyet, vb.) sürekli verilerden aldıkları puan ortalamalarının karşılaştırılmasında Mann Whitney U Testi; ikiden fazla olan grupların (eğitim durumu, vb.) sürekli verilerden aldıkları puanların ortalamalarının karşılaştııılmasında ise Kruskal Wallis-H Testi kullanılmıştır.

\section{Bulgular}

Katılımcıların betimsel olarak tanımlanması adına, sosyo-demografik özelliklerinin dağılımı Tablo 1'deki gibidir. 
Koronavirüs (COVID-19) Salgınında Sosyodemografik Özellikler, Psikolojik Sağlamlık... 85

\begin{tabular}{|c|c|c|}
\hline \multicolumn{3}{|c|}{ Tablo 1: Katılımcıların Sosyo-Demografik Özellikleri } \\
\hline & Kişi Sayısı & Yüzdelik Oranı \\
\hline \multicolumn{3}{|l|}{ Cinsiyet } \\
\hline Kadın & 342 & 65.10 \\
\hline Erkek & 182 & 34.70 \\
\hline Diğer & 1 & 0.20 \\
\hline \multicolumn{3}{|l|}{ Medeni Durum } \\
\hline Evli & 226 & 43 \\
\hline Bekar & 299 & 57 \\
\hline \multicolumn{3}{|l|}{$\overline{\text { Ĕgitim Düzeyi }}$} \\
\hline Okur-yazar & 1 & 0.20 \\
\hline İlkokul & 5 & 1 \\
\hline Ortaokul & 11 & 2.10 \\
\hline Lise & 57 & 10.90 \\
\hline Önlisans & 56 & 10.70 \\
\hline Lisans & 325 & 61.90 \\
\hline Lisansüstü & 70 & 13.30 \\
\hline \multicolumn{3}{|c|}{ Evde yaşayan kişi sayısı } \\
\hline Yalnız yaşayan & 36 & 6.90 \\
\hline İki & 116 & 22.10 \\
\hline Üç & 125 & 23.80 \\
\hline Dört & 134 & 25.50 \\
\hline Beş veya fazla & 114 & 21.70 \\
\hline \multicolumn{3}{|l|}{ Yaşantlan İ } \\
\hline İstanbul & 260 & 49.50 \\
\hline Ankara & 16 & 3 \\
\hline İzmir & 3 & 0.60 \\
\hline Antalya & 9 & 1.70 \\
\hline Diğer & 227 & 43.20 \\
\hline \multicolumn{3}{|l|}{ Kronik Hastalık } \\
\hline Yok & 416 & 79.20 \\
\hline Var & 109 & 20.80 \\
\hline
\end{tabular}

Çalışmanın örneklemini, 1 (\%0.20) "diğer", 342 kadın (\%65.10) ve 182 erkek (\%34.70) oluşturmuş̧ur. Katılımcıların 226'sı (\%43) evli olduğunu, 299'u (\%57) bekar olduğunu ifade etmiş̧tir. Yaşadıkları illere bakıldığında; katılımcıların \%49.50 ( $\mathrm{N}=260)$ oranında İstanbul'da yaşadığı görülmektedir. İstanbul dışında, Kayseri (\%13.10, $\mathrm{N}=69)$, Sivas $(\% 3.80, \mathrm{~N}=20)$ ve Bursa'dan $(\% 5, \mathrm{~N}=26)$ katılımın kalan illere göre fazla olduğunu söylemek mümkündür. Katılımcıların \%79.20'sinin ( $=412)$ kronik bir rahatsızlığı olmadığı; \%20.80'inin ise $(N=109)$ tanısı konulmuş kronik bir hastalığa sahip olduğu öğrenilmiştir. Katılımcılara ait, salgın sürecine yönelik ek bilgiler Tablo 2'deki gibidir. 
Tablo 2: Katılımcilara Ait Ek Bilgiler

\begin{tabular}{|c|c|c|}
\hline & Kişi Sayısı & Yüzdelik Oranı \\
\hline Salgın Öncesi Çalışma & & \\
\hline \multicolumn{3}{|l|}{ Durumu } \\
\hline Tam zamanlı kamu & 126 & 24 \\
\hline Tam zamanlı özel & 126 & 24 \\
\hline Öğrenci & 124 & 23.60 \\
\hline Çalışmıyor & 66 & 12.60 \\
\hline Emekli & 45 & 8.60 \\
\hline Yar1-zamanlı & 25 & 4.80 \\
\hline Staj & 13 & 2.50 \\
\hline \multicolumn{3}{|l|}{ İş Durumunda Değişiklik } \\
\hline Uzaktan çalışma & 84 & 38.20 \\
\hline Nöbet sistemine geçiş & 65 & 29.50 \\
\hline İdari izin & 45 & 20.50 \\
\hline Ücretsiz izin & 14 & 6.40 \\
\hline İşten çıkarılma/kapatma & 12 & 5.50 \\
\hline Toplam & 220 & 100 \\
\hline \multicolumn{3}{|l|}{ Ekonomik endişe } \\
\hline Var & 408 & 77.70 \\
\hline Yok & 117 & 21.30 \\
\hline \multicolumn{3}{|l|}{ Dışarı çıkma } \\
\hline Mecbur oldukça & 344 & 65.50 \\
\hline Hayır & 151 & 28.80 \\
\hline Evet & 30 & 5.70 \\
\hline \multicolumn{3}{|l|}{ Yeterli iletişim } \\
\hline Evet & 314 & 53.80 \\
\hline Hayır & 211 & 40.20 \\
\hline
\end{tabular}

Katılımcılardan özel sektörde ve kamu sektöründe tam zamanlı çalışan grubun en yüksek kesimi oluşturduğu ve onları öğrencilerin takip ettiği görülmüştür. Salgın öncesi çalışmakta olan katılımcılardan $(\mathrm{N}=290)$, \%72.40'ının $(\mathrm{N}=220)$ çalışma durumlarında bir değişiklik olduğu görülmüştür. $\mathrm{Bu}$ gruptan sadece \%5.50'si işine son verildiğini ya da işini kapatmak zorunda kaldığını aktarırken, büyük oranda uzaktan çalışma sistemine geçildiği öğrenilmiştir. Ayrıca, 408 kişi (\%77.70) salgın sebebiyle ekonomik endişelerinin olduğunu söylerken, kalan 117 kişi (\%22.30) endişelerinin olmadığını belirtmiştir. Salgın sürecinde 314 kişi (\%59.80) yakınlarıyla yeterince iletişim kurabildiğini düşündüğünü ifade etmiş; 211 kişi ise $(\% 40.20)$ yeterli iletişim içerisinde olduklarını düşünmediğini aktarmıştır.

\section{Betimsel Analizler}

Mevcut araştırma kapsamında, katılımcıların Beck Anskiyete Ölçeği’nden aldıkları ortalama puan 9.91, Kısa Psikolojik Sağlamlık Ölçeği'nden aldıkları ortalama puan ise 19.94 olarak bulunmuştur. Ayrıca, katılımcılara çeşitli hastalık ve riskleri yaşama olasılıklarını "1- Hiç olas1 değil" ve "4- Çok olası" aralığında değerlendirmeleri istenmiştir. Ayrıca koronavirüs hakkında bilgi aldıkları kaynakları belirtmeleri istenmiştir. Alınan cevaplara yönelik analiz sonuçları Tablo 3 ’teki gibidir. 
Koronavirüs (COVID-19) Salgınında Sosyodemografik Özellikler, Psikolojik Sağlamlık... 87

\begin{tabular}{|c|c|c|c|}
\hline \multicolumn{4}{|c|}{ Tablo 3: Betimsel Analiz Sonuçları } \\
\hline Kişisel Risk Olasılık Algısı & Ortalama & $\begin{array}{c}\text { Standart } \\
\text { Sapma }\end{array}$ & Aralık \\
\hline Grip / nezle & 3.12 & 0.63 & $1-4$ \\
\hline Koronavirüs & 2.87 & 0.69 & $1-4$ \\
\hline Ev kazası & 2.77 & 0.74 & $1-4$ \\
\hline Trafik kazası & 2.60 & 0.82 & $1-4$ \\
\hline Gida zehirlenmesi & 2.55 & 0.78 & $1-4$ \\
\hline Kanser & 2.50 & 0.79 & $1-4$ \\
\hline HIV / Aids & 1.71 & 0.82 & $1-4$ \\
\hline Coronavirüs Bilgi Kaynaklart & Kişi Sayısı & \multicolumn{2}{|c|}{ Yüzdelik Oranı } \\
\hline İnternet & 507 & \multicolumn{2}{|c|}{96.60} \\
\hline Televizyon & 453 & \multicolumn{2}{|c|}{86.30} \\
\hline Arkadaşlar/akrabalar & 264 & \multicolumn{2}{|c|}{50.30} \\
\hline Gazete & 102 & \multicolumn{2}{|c|}{19.40} \\
\hline Sağlık merkezleri & 83 & \multicolumn{2}{|c|}{15.80} \\
\hline Bilgi almiyor & 7 & \multicolumn{2}{|c|}{1.30} \\
\hline
\end{tabular}

Kişilerin grip veya nezle olma ihtimallerini en yüksek derecede algılarken, bunu koronavirüs olma ihtimalinin takip ettiği görülmektedir. Katılmcıların \%96.60 oranında bir kesiminin koronavirüs hakkında internet üzerinden bilgi aldığı görülmüştür.

Son olarak katılımcılardan COVID-19'a karşı çeşitli önleyici davranışlarda bulunup bulunmadıklarını belirtmeleri istenmiştir. Katılımcıların önleyici davranışlarına yönelik dağılım Tablo 4'teki gibidir.

Tablo 4: Önleyici Davranışlar Dağılımı

\begin{tabular}{|c|c|c|}
\hline & Kişi Sayısı & Yüzdelik Oranı \\
\hline Ellerimi daha sık yıkıyorum. & 503 & 95.80 \\
\hline $\begin{array}{l}\text { El sıkışmaktan / insanlarla } \\
\text { temas etmekten kaçınıyorum. }\end{array}$ & 492 & 93.70 \\
\hline $\begin{array}{l}\text { Genel hijyenime daha çok } \\
\text { dikkat ediyorum. }\end{array}$ & 468 & 89.10 \\
\hline $\begin{array}{l}\text { Toplu taşıma araçlarıyla } \\
\text { seyahat etmekten kaçınıyorum. }\end{array}$ & 450 & 85.70 \\
\hline $\begin{array}{l}\text { Yeterli süre uyumaya dikkat } \\
\text { ediyorum. }\end{array}$ & 381 & 72.60 \\
\hline Dezenfektan kullanıyorum. & 343 & 65.30 \\
\hline Dengeli besleniyorum. & 317 & 60.40 \\
\hline $\begin{array}{l}\text { Maske ve/veya eldiven } \\
\text { kullanıyorum. }\end{array}$ & 256 & 48.80 \\
\hline Gida takviyesi alıyorum. & 208 & 39.60 \\
\hline $\begin{array}{l}\text { Düzenli olarak egzersiz } \\
\text { yapiyorum. }\end{array}$ & 134 & 25.50 \\
\hline
\end{tabular}

Tablo 4'te görüldüğü üzere; ellerini daha sık yıkama davranışı çok yüksek oranda bulunurken, \%93.70 gibi yakın bir oranla kişilerin el sıkışmaktan kaçınmaya başladığı tespit edilmiştir. Düzenli olarak egzersiz yapma davranışının ise en az oranda gözlemlendiği öğrenilmiş̧tir. 


\section{Açımlayıcı Faktör Analizi(AFA)}

Ölçeklerin mevcut araştırma kapsamındaki faktör yapısını değerlendirmek amacıyla AFA uygulanmıştır. Verilerin faktörlenebilirlik değerlendirmesi amacıyla KMO katsayısı ve Barlett Küresellik Testi yapılmıştır. Faktör analizine uygunluk için KMO değerinin 0.60 'tan yüksek ve Barlett ki-kare değerinin anlamlı çıkması gerekmektedir (Büyüköztürk, 2004). BAÖ için KMO değeri 0.913 ve Barlett test sonucu $\chi 2=5098.446$ olarak; KPSÖ için KMO değeri 0.794 ve Barlett test sonucu $\chi 2=1001.914$ olarak bulunmuştur $(\mathrm{p}<0.000)$. Dolayısıyla faktör analizine devam edilmiştir. Döndürülmüş faktör analizi (Varimax) sonucunda; BAÖ için toplam varyansın \%38.91'ini, KPSÖ için toplam varyansın \%50.51'ini açıklayan tek faktörlü bir yap1 tespit edilmiştir.

\section{Korelasyon Analizi}

Araştırma kapsamında; yanıtların toplanması yaklaşımı ile faktör puanları hesaplanmıştır. Verilerin normal dağılım gösterip göstermediklerini anlamak amaciyla Kolmogorov-Smirnov testi uygulanmıştır. Sonuç olarak, verilerin hem BAÖ $(\mathrm{D}(525)=0.156, \mathrm{p}=0.000)$ için hem de KPSÖ $(\mathrm{D}(525)=0.063, \mathrm{p}=0.000)$ için normal dağılmadığ 1 tespit edilmiştir. Bu sebeple, parametrik olmayan testlerden olan Spearman korelasyon analizi kullanılmıştır. Sonuçlar Tablo 5'teki gibidir.

Tablo 5: Faktörler Arası Korelasyon Analizi

\begin{tabular}{|c|c|c|c|c|c|}
\hline & & $\begin{array}{l}\text { Psikolojik } \\
\text { Sağlamlık }\end{array}$ & Anksiyete & $\begin{array}{l}\text { Koronavirüs } \\
\text { AlgıSI }\end{array}$ & Önleyici Davranışlar \\
\hline $\begin{array}{l}\text { Psikolojik } \\
\text { Sağlamlık }\end{array}$ & & 1.000 & $-0.453 * *$ & -0.047 & $0.103^{*}$ \\
\hline Anksiyete & & & 1.000 & $0.177 * *$ & -0.027 \\
\hline $\begin{array}{l}\text { Koronavirüs } \\
\text { AlgıS! }\end{array}$ & Risk & & & 1.000 & 0.002 \\
\hline $\begin{array}{l}\text { Önleyici } \\
\text { Davranışlar }\end{array}$ & & & & & 1.000 \\
\hline
\end{tabular}

**0.01,*0.05 düzeyinde istatistiksel olarak anlamlıdır.

Psikolojik sağlamlık ve anksiyete arasında negatif yönde anlamlı bir ilişki saptanmıştır ( $\mathrm{r}=$ $-0.453, \mathrm{p}<0.01)$. Bu sonuç, psikolojik sağlamlık arttıkça anksiyete düzeylerinin azaldığ 1 anlamına gelmektedir. Ayrıca, kişilerin koronavirüse yakalanma olasıllı̆ı algısı ve anksiyete arasında pozitif yönde anlamlı bir ilişki saptanmıştır $(\mathrm{r}=0.177, \mathrm{p}<0.01)$. Kişilerin algıladıkları hastalığa yakalanma ihtimali arttıkça anksiyete düzeyleri artmaktadır. Önleyici davranışlarda bulunma puanlarının toplamından elde edilen değişkenle ilişkiler incelendiğinde, psikolojik sağlamlıkla aralarında pozitif yönde anlamlı bir ilişki olduğu görülmüştür $(r=0.103, p<0.01)$. Psikolojik sağlamlık düzeyi arttıkça önleyici davranışlarda bulunma düzeyi de artmaktadır. Öte yandan, evde yaşayan kişi sayısıyla anksiyete ve psikolojik sağlamlık arasında herhangi bir anlamlı ilişki tespit edilmemiştir (sirasiyla $\mathrm{r}=0.060 ; \mathrm{r}=-0.068, \mathrm{p}>0.05$ ).

\section{Sosyo-Demografik Özellikler ve Ölçekler Arasındaki IIlişkiler}

Verilerin normal dağılmaması sebebiyle parametrik olmayan testler aracılığıyla katılımcıların sosyo-demografik bilgileriyle anksiyete ve psikolojik sağlamlık düzeyleri arasındaki ilişkiler incelenmiştir. Tablo 6'da görüldüğü üzere, yapılan Mann-Whitney U Testi sonucunda kadınların anksiyete düzeylerinin erkeklerden yüksek $(\mathrm{U}=18787.00, \mathrm{p}=0.00)$ ve psikolojik sağlamlık düzeylerinin düşük olduğu görülmüştür $(\mathrm{U}=23690.00, \mathrm{p}=0.00)$. 
Koronavirüs (COVID-19) Salgınında Sosyodemografik Özellikler, Psikolojik Sağlamlık... 89

Tablo 6: Cinsiyet Değişkenine göre Mann-Whitney U Testi Sonuçları

\begin{tabular}{ccccccc}
\hline Ölçek & Grup & $\begin{array}{c}\text { Katılımcı } \\
\text { Sayısı }\end{array}$ & $\begin{array}{c}\text { Srra } \\
\text { Ortalaması }\end{array}$ & Sıra Toplamı & U & Anlamlılık Değeri \\
\hline BAÖ & Kadın & 342 & 298.57 & 102110.00 & 18787.00 & 0.000 \\
& Erkek & 182 & 194.73 & 35440.00 & & 0.000 \\
KPSÖ & Kadın & 342 & 240.77 & 82343.00 & 23690.00 & \\
& Erkek & 182 & 303.34 & 55207.00 & & \\
\hline
\end{tabular}

Salgın sebebiyle ekonomik endişeleri olan grubun anksiyete düzeylerinin daha yüksek olduğu $(U=19453.500, p=0.002)$, psikolojik sağlamlık açısındansa herhangi bir fark olmadığı görülmüştür ( $\mathrm{U}=23044.500, \mathrm{p}>0.05)$ (Tablo 7).

Tablo 7: Ekonomik Endişe Değişkenine göre Mann-Whitney U Testi Sonuçları

\begin{tabular}{ccccccc}
\hline Ölçek & Grup & $\begin{array}{c}\text { Katılıme } \\
\text { Sayısı }\end{array}$ & $\begin{array}{c}\text { Sıra } \\
\text { Ortalaması }\end{array}$ & Sıra Toplamı & U & Anlamlısk Değeri \\
\hline BAÖ & Var & 408 & 273.82 & 111718.50 & 19453.500 & 0.002 \\
& Yok & 117 & 225.27 & 26356.50 & & 0.568 \\
KPSÖ & Var & 408 & 260.98 & 260.98 & 23044.500 & 0.568 \\
& Yok & 117 & 270.04 & 270.04 & & \\
\hline
\end{tabular}

Salgın öncesi çalışma durumuna göre gruplar Kruskal-Wallis H-testiyle incelendiğinde anksiyete açısından anlamlı bir fark bulunmazken psikolojik sağlamlık açısından gruplar arası anlamlı bir fark olduğu görülmüştür (sırasıyla $\chi_{(\mathrm{sd}=6, \mathrm{n}=525)}^{2}=9.776, \mathrm{p}=0.134 ; \chi_{(\mathrm{sd}=6, \mathrm{n}=525)}=$ 14.896, $\mathrm{p}=0.021)$. Yapılan izleme analizleri sonucu öğrenci grubun psikolojik sağlamlık düzeylerinin emekli $(p=0.042)$ ve özel sektörde tam zamanlı çalışan gruba $(p=0.024)$ göre daha düşük olduğu görülmüştür (Tablo 8).

Tablo 8: Çalı̧̧ma Durumu Değişkenine göre Kruskal Wallis H-Testi Sonuçları

\begin{tabular}{|c|c|c|c|c|c|c|}
\hline & Grup & Katılımeı Sayısı & Sira ort. & SD & $\chi^{2}$ & $\mathbf{p}$ \\
\hline \multirow[t]{7}{*}{ BAÖ } & Çalışmıyor & 66 & 261.55 & 6 & 9.776 & 0.134 \\
\hline & Staj & 13 & 304.08 & & & \\
\hline & $\begin{array}{l}\text { Yar1-zamanlı } \\
\text { çalışma }\end{array}$ & 25 & 239.32 & & & \\
\hline & $\begin{array}{l}\text { Tam-zamanlı } \\
\text { özel sektör }\end{array}$ & 126 & 249.69 & & & \\
\hline & $\begin{array}{l}\text { Tam-zamanlı } \\
\text { kamu }\end{array}$ & 126 & 256.33 & & & \\
\hline & Öğrenci & 124 & 294.73 & & & \\
\hline & Emekli & 45 & 234.93 & & & \\
\hline \multirow[t]{7}{*}{ KPSÖ } & Çalışmıyor & 66 & 250.52 & 6 & 14.896 & $0.021 *$ \\
\hline & Staj & 13 & 244.81 & & & \\
\hline & $\begin{array}{l}\text { Yarı-zamanlı } \\
\text { çalışma }\end{array}$ & 25 & 272.50 & & & \\
\hline & $\begin{array}{l}\text { Tam-zamanlı } \\
\text { özel sektör }\end{array}$ & 126 & 281.28 & & & \\
\hline & $\begin{array}{l}\text { Tam-zamanl } \\
\text { kamu }\end{array}$ & 126 & 282.57 & & & \\
\hline & Öğrenci & 124 & 222.21 & & & \\
\hline & Emekli & 45 & 287.70 & & & \\
\hline
\end{tabular}

* 0.05 düzeyinde istatistiksel olarak anlamlıdır. 
Salgın sürecinde dışarı çıkma durumuna göre gruplar arasında anlamlı bir fark olup olmadığının tespiti için yapılan Kruskal-Wallis H-testi, katılımcıların anksiyete ve psikolojik sağlamlık puanlarının anlamlı bir şekilde değiştiğini göstermiştir (sırasıyla $\chi_{(\mathrm{sd}=2, \mathrm{n}=525)}^{2}=7.507, \mathrm{p}$ $\left.=0.023 ; \chi_{(\mathrm{sd}=2, \mathrm{n}=525)}=6.231, \mathrm{p}=0.044\right)$. Yapılan izleme analizi sonucu, salgın sürecinde dişarı çıkmayı sürdüren kişilerin anksiyete düzeylerinin hiç çıkmayan gruptan $(p=0.002)$ ve mecbur kaldıkça çıkan gruptan $(\mathrm{p}=0.002)$ anlamlı derecede daha düşük olduğu görülmüştür. Psikolojik sağlamlık açısından bakıldığında, mecbur kaldıkça dışarı çıkan grubun hiç çıkmayan gruba göre anlamlı düzeyde daha yüksek olduğu tespit edilirken $(\mathrm{p}=0.04)$ diğer gruplar arasında herhangi bir fark bulunmamıştır ( $\mathrm{p}>0.05$ ) (Tablo 9).

Tablo 9: Dışarı Çıkma Değișkenine göre Kruskal Wallis H-Testi Sonuçları

\begin{tabular}{llccccc}
\hline & Grup & Katılıme Sayısı & Sıra ort. & SD & $\chi^{\mathbf{2}}$ & p \\
\hline BAÖ & Evet & 30 & 189.77 & 2 & 7.507 & $0.023^{*}$ \\
& & & & & & \\
& Hayır & 151 & 270.13 & & & \\
& Mecbur kaldıç̧a & 344 & 266.26 & & & \\
KPSÖ & 30 & 285.03 & 2 & 6.231 & $0.044^{*}$ \\
& Evet & & & & & \\
& Hayır & 151 & 237.47 & & & \\
& Mecbur kaldıkça & 344 & 272.28 & & & \\
& & & & & & \\
\end{tabular}

* 0.05 düzeyinde istatistiksel olarak anlamlıdır.

Salgın sürecinde yakınlarıyla yeterince iletişim kurabildiğini düşünen grubun düşünmeyen gruba kıyasla anksiyete düzeyleri daha düşük bulunmuştur $(\mathrm{U}=28649.500, \mathrm{p}=0.009)$. Öte yandan, psikolojik sağlamlık düzeyleri daha yüksek bulunmakla birlikte, anlamlı düzeyde bir fark olmadığı görülmüştür ( $\mathrm{U}=29999.50, \mathrm{p}=0.066)$ (Tablo 10).

Tablo 10: İletişim Değişkenine göre Mann-Whitney U Testi Sonuçları

\begin{tabular}{ccccccc}
\hline Ölçek & Grup & $\begin{array}{c}\text { Katılımc } \\
\text { Sayısı }\end{array}$ & $\begin{array}{c}\text { Sıra } \\
\text { Ortalaması }\end{array}$ & Sıra Toplamı & U & Anlamlılık Değeri \\
\hline BAÖ & Yeterli & 314 & 248.74 & 78104.50 & 28649.500 & 0.009 \\
& Yetersiz & 211 & 284.22 & 59970.50 & & 0.066 \\
KPSÖ & Yeterli & 314 & 272.96 & 85709.50 & 29999.50 & \\
& Yetersiz & 211 & 248.18 & 52365.50 & & \\
\hline
\end{tabular}

Öte yandan; evli ve bekar grup arasında, eğitim düzeyleri, yaşanılan il açısından, salgın sebebiyle çalışma durumunda değişiklik olan ve olmayan gruplar arasında ve iş durumu değişen grupların kendi aralarında da anksiyete ve psikolojik sağlamlık açısından herhangi bir fark tespit edilmemiştir ( $\mathrm{p}>0.05)$.

\section{Tartışma ve Sonuç}

Araştırma kapsamında katılımcıların sosyo-demografik özellikleri incelenirken COVID-19 pandemisinde çalışma yaşamlarının nasıl etkilendiği cevap aranan en önemli sorulardan biri olmuştur. COVID-19 salgınıyla beraber, çalışmakta olan katılımcıların \%27.60'1 çalışma sisteminde herhangi bir değişiklik olmadığını söylerken geriye kalan katılımcılar ise çalışma durumlarında bir değişiklik olduğunu belirtmiştir. Çalışma sisteminde değişiklik olan katılımcılar bu değişikliklerin uzaktan çalışma, nöbetleşe çalışma, idari izinli olma, ücretsiz izinli olma gibi değişiklikler olduğunu söylerken katılımcıların \%5.50'si işine son verildiğini ya da işini kapatmak 
zorunda kaldığını, katılımcıların \%6.40’1 ise ücretsiz izinde olduklarını aktarmıştır. Bu sonuçlara bakıldığında bireylere sunulacak psikososyal desteklerin yanı sıra ekonomik desteğin de süreç boyunca önemli olacağı kanaati oluşmuştur. İnsanların önemli bir oranda işlerini kaybettiği veya karantina sürecinde çalışamadığı görülmektedir. Araştırma verilerinin Mart ayında toplandığı düşünüldüğünde, salgından kaynaklı işsizlik oranın ilerleyen süreç içerisinde artabileceği ve bu durumun etkisini uzun süre göstereceği düşünülmektedir. Söz konusu çalışma kapsamında yine katılımcıların \%77.70'inin ekonomik endişelerinin var olduğu tespit edilmiş ve ekonomik endişeleri yüksek olan katılımcıların salgın dönemi kaygı düzeylerinin daha yüksek olduğu bulgulanmıştır.

Olumlu duyguların zorlu yaşam olayları karşısında başa çıkma becerileri geliştirmede faydalı olabileceği ve bu olumlu duyguların sağlık için önemli olduğu yönünde çalışmalar mevcuttur. Yapılan birçok araştırma olumlu duygular ile psikolojik sağlamlık arasında pozitif bir ilişki olduğunu ifade etmektedir (Tugade, Fredrickson \& Feldman Barrett, 2004). Bu çalışmada katılımcıların sosyo-demografik özellikleri ile ölçekler arasındaki ilişkiler incelendiğinde ise, psikolojik sağlamlık arttıķa anksiyete düzeylerinin azaldığı tespit edilmiştir. Yani COVID-19 salgınının ortaya çıkardığı zor koşullara karşın, kişilerin bu zor koşulların üstesinden başarıyla gelebilme ve uyum sağlayabilme yeteneği arttıkça bu hastalığa yönelik kaygı düzeylerinin azaldığı görülmüştür. $\mathrm{Bu}$ bağlamda sosyal hizmet uygulama modellerinden biri olan krize müdahale yaklaşımının ve psikososyal destek çalışmalarının pandemi sürecinde toplumda ruh sağlığının korunması için önem arz edeceği düşünülmektedir. Sunulabilecek psikososyal destek çalışmalarında, bireylerin kendi kapasitelerini fark etmelerinin sağlanmasına ve güçlendirilmelerine yardımcı olmak için meslek elemanları ihtiyaçları net bir biçimde belirlemeli ve ona göre müdahale sürecini şekillendirmelidir (Y1ldırım, 2016).

Olumlu duyguların sağlık için iyi olduğu fikri popüler bir görüştür ve yine bu görüşü destekleyen çok sayıda teori ve araştırma mevcuttur. Fredrickson (1998; 2001), "pozitif duygu genişletme ve inşa etme teorisi" ile (broaden-and-build theory of positive emotions) olumlu duyguların sağlığa pek çok açıdan yararlı olduğunu ileri sürmüş̧ür. Olumlu duygular, sağlıklı bir yaşamı destekleyen koruyucu bir faktör olarak bilinir (Fredrickson, 2001; Tugade ve ark., 2004). $\mathrm{Bu}$ çalışmada kişilerin hastalığa yakalanma ihtimali yönündeki algısı arttıkça anksiyete düzeylerinin de arttığı görülmüştür. Önleyici davranışlarda bulunma düzeyleri ve psikolojik sağlamlık arasında pozitif yönde anlamlı bir ilişki olduğu bulgulanmıştır. Diğer bir deyişle katılımcıların psikolojik sağlamlık düzeyi arttıkça önleyici davranışlarda bulunma düzeyi de artmaktadır. COVID-19'a karşı çeşitli önleyici davranışlarda bulunup bulunmadıkları sorulduğunda katılımcıların büyük çoğunluğunun ellerini sık sık yıkamaya başladığı, insanlarla el sıkışmaktan kaçındığ 1 ve genel hijyenine daha çok dikkat etmeye başladığ 1 tespit edilmiştir. Öte yandan; evde yaşayan kişi sayısı, katılımcıların evli ya da bekar olma durumu, eğitim düzeyleri ve yaşadıkları ilin katılımcıların kaygı ve psikolojik sağlamlık düzeylerini etkilemediği görülmüştür.

Psikolojik sağlamlık teorik olarak kendini çabuk toparlayabilen insanların stresli yaşam deneyimleri karşısında hızlı ve yeterli olarak geriye tekrar dönebilmesi olarak tanımlanır (Carver, 1998). Çalışma sonucunda, COVID-19 pandemisinde kadınların erkeklere göre kaygı düzeylerinin daha yüksek olduğu ve kadınların psikolojik sağlamlık düzeylerinin daha düşük olduğu bulgulanmıştır. Ekiz ve arkadaşlarının (2020) yaptığı bir çalışmada da kadınların sağlık anksiyetesi düzeylerinin erkeklerden daha yüksek olduğu bulgulanmıştır. Benzer bir araştırmada ise psikolojik dayanıklılık ve cinsiyet arasında bir ilişki olduğu görülmüş ve erkeklerin psikolojik dayanıklılığının daha yüksek olduğu bulgulanmıştır (Bonanno ve ark., 2008).

Bazı çalışmalarda ise olumsuz duygudurumların düşmanlık, öfke ve anksiyete; kalp hastalıkları ve hipertansiyon gibi kronik hastalıkların kökeninde rol oynadığına değinilmiştir (Blascovich, 1993). COVID-19 pandemisi sürecinde Türkiye'de yapılan bir araştırmada kadınların durumluk-sürekli kaygı düzeylerinin erkeklere oranla daha yüksek olduğu görülmüştür (Çölgeçen 
\& Çölgeçen, 2020). Benzer şekilde Göksu ve Kumcağız da (2020) yaptıkları çalışmada kadınların algılanan stres ve kaygı düzeylerinin erkeklerden daha yüksek olduğunu bulgulamışlardır. Bu sonuçlar, psikososyal koruyucu müdahaleler geliştirilirken cinsiyete dayalı farklılıkların da göz önünde bulundurulmasının etkili olacağına işaret etmektedir.

Mevcut çalışmada, salgın sürecinde yakınlarıyla yeterince iletişim kurabildiğini düşünen grubun düşünmeyen gruba kıyasla kaygı düzeyleri daha düşük ve psikolojik sağlamlık düzeyleri daha yüksek bulunmuştur. Yani salgın sürecinde yakınlarıyla iletişim (telefon, internet ortamında görüşme) kuran bireyler daha az kaygıya sahipken aynı zamanda psikolojik sağlamlıklarının daha yüksek olduğu görülmüştür. COVID-19'a yakalanan bireylerin bu hastalığı atlatabilmeleri için bağışıklık sisteminin güçlü olması gerektiği ve olumsuz duyguların farklı hastalıklara neden olduğu düşünüldüğünde; salgın sürecinde yakınlarıyla yeterince iletişim kurabilmenin bireylerin ruh sağlıklarını koruyabilmeleri açısından önem arz ettiği düşünülmektedir. $\mathrm{Bu}$ doğrultuda değerlendirilebilecek bir diğer bulgu ise salgın sürecinde dışarı çıkmayı sürdüren kişilerin anksiyete düzeylerinin hiç çıkmayan gruptan ve mecbur kaldıkça çıkan gruptan anlamlı derecede daha düşük olduğudur. Ayrıca psikolojik sağlamlık açısından bakıldığında, mecbur kaldıkça dışarı çıkan grubun hiç çıkmayan gruba göre anlamlı düzeyde daha yüksek değerlere sahip olduğu görülmüştür.

Üstün ve Özçiftçi'nin (2020) COVID-19 pandemisinin sosyal yaşama etkilerini değerlendirdikleri çalışmalarında; seyahat özgürlüklerine gelen yasaklar, uzaktan eğitim sistemine geçiş ile evden eğitim verilmeye başlanması ve ekonomik sorunlar gibi pek çok alan ele alınmıştır. $\mathrm{Bu}$ süreçte gerçekleştirilen bir başka çalışmada; pandemik kaygının psikolojik iyi oluş üzerindeki olumsuz etkisi kamuda yok denecek kadar az iken özel sektörde bu etkinin çok daha yüksek olduğu ve pandemik kaygının özel sektör çalışanlarını daha fazla sarstığı tespit edilmiştir (Çiçek ve Almal1, 2020). Birçok haberde ve köşe yazılarında paylaşılan "COVID-19 pandemisinden sonra artık hiçbir şeyin eskisi gibi olmayacağı" varsayımı ülkelerin politik, ekonomik ve sağlık alanı gibi pek çok alanda oluşturulacak politikaları etkileyeceği düşünülmektedir. Bu bağlamda, yapılacak gelecek çalışmaların COVID-19'un bireyler ve toplumlar üzerindeki uzun süreli psikososyal etkilerini araştırmalarının faydalı olacağı düşünülmektedir.

COVID-19 pandemi sürecinde Türkiye'de yaşayan bireylerin mevcut yaşam düzenlerinin pek çok açıdan etkilendiği görülmüştür. Bu değişiklikler ve COVID-19 yüzünden yaşanan ölümler nedeniyle, bireyler bu hastalıktan korunmak için söz konusu virüse karşı çeşitli önleyici davranışlarda bulunmaya başlamışlar ve kişisel temizliklerine daha fazla önem vermeye başlamışlardır. Her ne kadar Türkiye'de 01.06.2020 tarihinde "yeni normal" adı altında salgın öncesi çalışma düzenine geri dönülse de, elbette ki Dünya Sağlık Örgütü tarafindan "Uluslararası Kamu Sağlığı Acil Durumu" ilan edilen bu durumun insanların ruh sağlı̆̆ üzerindeki etkisi sürmektedir ve sürmeye devam edeceği düşünülmektedir.

Araştırma sonuçları ışığında, sosyal hizmetler ve psikososyal müdahaleler kapsamında çeşitli adımlar atılmasının yerinde olacağı düşünülmektedir. Öncelikle, salgın nedeniyle işini kaybedenlere ve ekonomik açıdan sıkıntı yaşayan bireylere ekonomik destek verilmesi ve yeni istihdam olanakları yaratılmasının faydalı olacağı düşünülmektedir. Ayrıca, COVID-19 nedeniyle yakınlarını kaybedenlere salgın sürecinde ve sonrasında sağlanacak psikososyal destek çalışmalarına ihtiyaç duyulmaktadır.

Gelecek çalışmalar açısından bakıldığında; salgın süreci boyunca meydana gelecek gelişmelere göre insanların kaygı ve psikolojik sağlamlık düzeylerinin farklılık göstereceği düşünülmektedir. Dolayısıyla bu konuyla ilgili araştırmaların güncelliğini koruması açısından bu değişkenleri sistematik olarak incelemesi faydalı olacaktır.

Son olarak, salgının olumsuz etkilerini gidermek için kanıta dayalı sosyal hizmet uygulamalarının sunulması amacıyla araştırma sonuçlarına ihtiyaç olduğu bilinmektedir. 
Salgın etkisinin birey, aile ve toplum bazında farklı sorunlara sebep olması sebebiyle, mevcut çalışmanın mikro, mezzo ve makro düzeyde planlanacak sosyal hizmet müdahalelerine katkı sağlayacağ1 düşünülmektedir. Araştırmada elde edilen sosyodemografik bilgilerin değerlendirilmesinin, salgına yönelik sosyal politikalar hazırlanırken katk1 sunabileceği düşünülmektedir.

\section{Kaynakça}

Alakara Özcan, G. (2018). Afetlerde psikososyal destek hizmetlerinin AFAD'da çalışan sosyal çalışmacılar tarafindan değerlendirilmesi. Yüksek Lisans Tezi, Sosyal Bilimler Enstitüsü: Hacettepe Üniversitesi. http://hdl.handle.net/11655/5105

Ankaral1, H., Ankaral1, S., \& Erarslan, N. (2020). COVID-19, SARS-CoV2, enfeksiyonu: Güncel epidemiyolojik analiz ve hastalık seyrinin modellemesi. Anadolu Kliniği Tıp Bilimleri Dergisi; 25(1), 1-22. https://doi.org/10.21673/anadoluklin.707038

Bag, M. (2020). Dünya'da Covid-19: Salgının ilk 100 gününde yaşananlar, ilk nerede ortaya çıtı? Nasıl yayıldı? Euronews. https://tr.euronews.com

Beck, A. T., Epstein, N., Brown, G., \& Steer, R. A. (1988). An inventory for measuring clinical anxiety: Psychometric properties. Journal of consulting and clinical psychology, 56(6), 893-897. https://doi.org/10.1037/0022-006X.56.6.893

Blascovich, J. J., \& Katkin, E. S. (Eds.) (1993). Cardiovascular reactivity to psychological stress \& disease. American Psychological Association.

Bonanno, G. A., Ho, S.M.Y., Chan, J.C.K., Kwong, R.S.Y., Cheung, C.K.Y., Wong, C.P.Y. ve Wong, V.C.W. (2008). Psychological resilience and dysfunction among hospitalized survivors of the sars epidemic in hong kong: a latent class approach. Health Psychology Copyright, 27(5): 659-667. https://doi.org/10.1037/0278-6133.27.5.659

Budak, F., \& Korkmaz, Ş. (2020). COVID-19 Pandemi sürecine yönelik genel bir değerlendirme: Türkiye örneği. Sosyal Araştırmalar ve Yönetim Dergisi, 62-79.

Büyüköztürk, Ş. (2004). Veri Analizi El Kitabı. Pegem A Yayıncılık.

Carver, C. S. (1998). Resilience and thriving: Issues, models, and linkages. Journal of Social Issues, 54(2), 245-266.

Çiçek, B., \& Almalı, V. (2020). COVID-19 pandemisi sürecinde kaygı öz-yeterlilik ve psikolojik iyi oluş arasındaki ilişki: Özel sektör ve kamu çalışanları karşılaştırması. Turkish Studies, 15(4), 241-260. https://dx.doi.org/10.7827/TurkishStudies.43492

Çölgeçen, Y., \& Çölgeçen, H. (2020). Covid-19 pandemisine bağl1 yaşanan kaygı düzeylerinin değerlendirilmesi: Türkiye örneği. Turkish Studies, 15(4), 261-275. https://dx.doi.org/10.7827/TurkishStudies.44399

Doğan, T. (2015). Kısa psikolojik sağlamlık ölçeği'nin Türkçe uyarlaması: Geçerlik ve güvenirlik çalışması. The Journal of Happiness \& Well-Being, 3(1), 93-102. https://toad.halileksi.net/sites/default/files/pdf/kisa-psikolojik-saglamlik-olcegi-toad.pdf

Ekiz, T., Ilıman, E., \& Dönmez, E. (2020). Bireylerin sağlık anksiyetesi düzeyleri ile COVID-19 salgını kontrol algısının karşılaştırılması. Uluslararası Sağlık Yönetimi ve Stratejileri Araştırma Dergisi, 6(1), 139-154.

Fredrickson, B. L. (1998). What good are positive emotions? Review of General Psychology, 2(3), 300-319. https://doi.org/10.1037/1089-2680.2.3.300 
Fredrickson, B. L. (2001). The role of positive emotions in positive psychology: The broaden-andbuild theory of positive emotions. American psychologist, 56(3), 218-226. https://doi.org/10.1037/0003-066X.56.3.218

Geçtan, E. (2012). Psikodinamik psikiyatri ve normaldışı davranışlar. (20. ed.). Metis Yayınları.

Göksu, Ö., \& Kumcağız, H. (2020). Covid-19 salgınında bireylerde algılanan stres düzeyi ve kayg1 düzeyleri. Turkish $\quad$ Studies, $463-479$. https://dx.doi.org/10.7827/TurkishStudies.44397

Holland, K. (2019) Everything you need to know about anxiety. Healthline (cited 2020 April 18). https://www.healthline.com/health/anxiety

IFRC. (2009). Community-Based Psychosocial Support. Denmark: International Federation of Red Cross and Red Crescent Societies. https://pscentre.org/?resource=community-basedpsyhosocial-support-trainers-book-english

Karcıoğlu, Ö. (2020). Coronavirüs nedir, nasıl korunabiliriz? Anka Tip Dergisi, 2(1), 66-71.

Lotfi, S., \& Başc1llar, M. (2017). Travma sonrası stres bozukluğu ve sosyal hizmet. IGUSABDER, 3, 275-86. https://hdl.handle.net/11363/604

Manav, F. (2011). Kaygı kavramı. Toplum Bilimleri Dergisi, 5(9), 201-11.

Öz, F., \& Bahadır Yılmaz, E. (2009). Ruh sağlığının korunmasında önemli bir kavram: Psikolojik sağlamlık. Hacettepe Üniversitesi Hemşirelik Fakültesi Dergisi, 16(3), 82-89. http://www.hacettepehemsirelikdergisi.org/pdf/pdf_HHD_87.pdf

Smith, B. W., Dalen, J., Wiggins, K., Tooley, E., Christopher, P., \& Bernard, J. (2008). The brief resilience scale: assessing the ability to bounce back. International journal of behavioral medicine, 15(3), 194-200. https://doi.org/10.1080/10705500802222972

Tugade, M. M., Fredrickson, B. L., \& Feldman Barrett, L. (2004). Psychological resilience and positive emotional granularity: Examining the benefits of positive emotions on coping and health. Journal of Personality, 72(6), 1161-1190. https://doi.org/10.1111/j.14676494.2004.00294.x

Ulusoy, M., Şahin, N, Erkman, H. (1998). Turkish version of The Beck Anxiety Inventory: psychometric properties. Journal of Cognitive Psychotherapy: An International Quarterly, 12(2), 28-35.

Üstün, Ç., \& Özçiftçi, S. (2020). COVID-19 pandemisinin sosyal yaşam ve etik düzlem üzerine etkileri: Bir değerlendirme çalışması. Anadolu Kliniği Tıp Bilimleri Dergisi, 25(1), 142153.

World Health Organization. (2020). Q\&A On Coronaviruses (COVID-19). https://www.who.int/news-room/q-a-detail/q-a-coronaviruses.

Yıldırım Ş. (2016). Sosyal hizmette krize müdahale yaklaşımının kullanımı. Celal Bayar Üniversitesi Sağllk Bilimleri Enstitüsü Dergisi, 3(4), 481-486. https://dergipark.org.tr/en/pub/cbusbed/issue/26662/272680 